\title{
Los movimientos campesinos en el Perú ${ }^{1}$
}

Aunque el Perú fue uno de los centros mundiales de domesticación de plantas; y aunque su sector rural ha sido el más importante de todos durante su historia, son todavía muy escasos los estudios sobre la agricultura y el campesinado andinos. Por lo menos el nivel historiográfico muy retrasado en esto, con respecto a la antropología científica impulsada por Luis E. Valcárcel desde 1946. De allí la importancia de este libro sobre los movimientos campesinos en el Perú ${ }^{2}$ donde por primera vez tenemos una visión de conjunto y una antología de las investigaciones hechas sobre el Campo durante los últimos diez años.

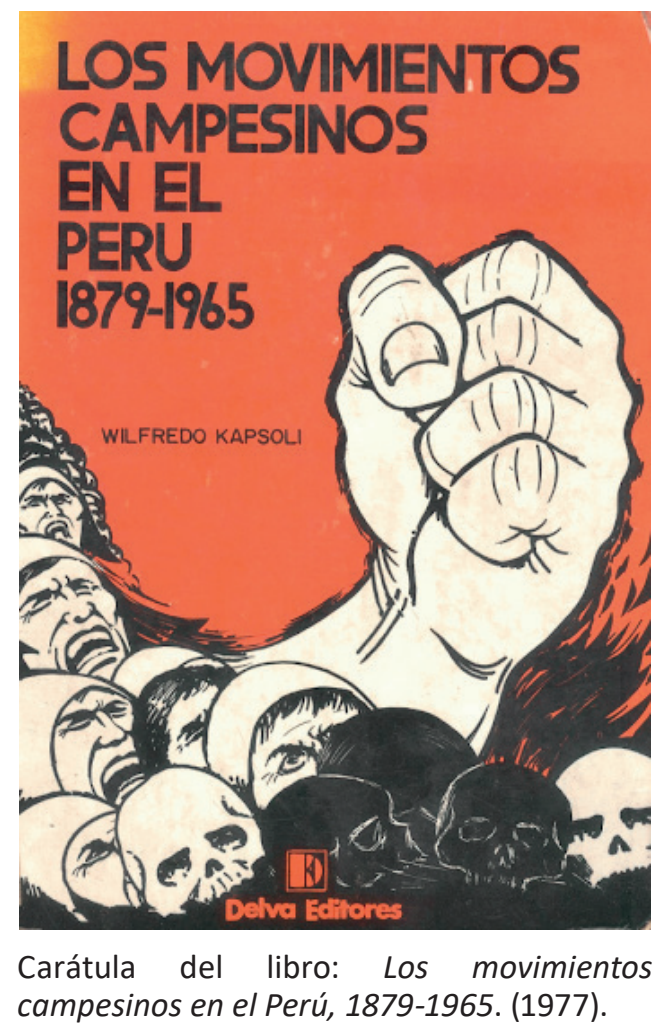

La obra es un caso de heroísmo editorial que debemos a Juan Salazar, uno de esos «libreros de cosas viejas» cada vez más raros y que son los mejores amigos y colaboradores del científico social. La iniciativa y el mérito principal de esta publicación es de Wilfredo Kapsoli ${ }^{3}$ un joven y ya 1 Tomado de: Diario La Prensa el 25-11-77, La Imagen Cultural.

2 “Los Movimientos Campesinos en el Perú, 1879-1965”. Delva Editores, Lima, Octubre de 1977; 308 pp.

3 Wilfredo Kapsoli estudió Educación e Historia en la UNMSM; nació en Pomabamba (Ancash) en 1945. Ha publicado “Situación del campesinado peruano 1919-1930", en colaboración con Wilson Reátegui; "Sublevación de esclavos en el Perú s. XVIII”; “Los movimientos campesinos en Cerro de Pasco: 1880-1963" y “Luchas obreras en el Perú: 1900-1919”. Actualmente es profesor en San Marcos en el Programa de Ciencias Histórico - Sociales.

(C) Los autores. Este artículo es publicado por ISHRA, Revista del Instituto Seminario de Historia Rural Andina de la Facultad de Ciencias Sociales de la Universidad Nacional Mayor de San Marcos. Este es un artículo de acceso abierto, distribuido bajo los términos de la licencia Creative Commons Atribución 4.0 Internacional (CC BY 4.0) [https://creativecommons.org/licenses/by/4.0/deed.es] que permite el uso, distribución y reproducción en cualquier medio, siempre que la obra original sea debidamente citada de su fuente original. 
logrado historiador sanmarquino que se ha mantenido fiel a su primera vocación de historiador, pese a sus obligaciones como autoridad universitaria. Cuando fue director en la Universidad Ricardo Palma, mucho temimos que hubiese suicidado su actividad científica. Este libro prueba lo contrario. Kapsoli ha seleccionado los seis estudios que constituyen la segunda parte del libro ${ }^{4}$ nos propone en su introducción una periodificación de los movimientos campesinos ocurridos en el Perú entre la guerra con Chile y las guerrillas conducidas por De la Puente y Lobatón. Es posible no estar de acuerdo con algunas de sus afirmaciones; discutir por ejemplo acerca de su caracterización del milenarismo; pero en todo momento reconocemos en esa introducción el estilo de un excelente historiador.

Los ensayos seleccionados por Kapsoli han sido escritos por jóvenes historiadores que iniciaron su carrera universitaria alrededor de 1965, en pleno belaundismo, y cuando hicieron crisis las relaciones entre ciudad y campo en el Perú. No se trata aquí de una simple coincidencia cronológica sino de una relación causal. Es obvio que Valladares, Rengifo, Burga, Reátegui, fueron impactados por la desesperación campesina de los años 60 y por el heroísmo lúcido e inútil de los intelectuales que lucharon al lado de esos campesinos. Esta es pues una literatura comprometida, no una diversión erudita. Lo mismo podemos decir de hombres más jóvenes como Alberto Flores Galindo y Manuel Manrique con sus trabajos sobre Arequipa y la selva del Perené.

Desde luego que no se encuentran en este volumen todas las investigaciones hechas últimamente sobre el campesinado. Esta no podía ni debía ser la intención de Kapsoli. No advertimos a veces cuan numerosos son hoy los centros y las gentes que estudian el sector agrario peruano.

Ahí están los talleres, y seminarios que funcionan en La Católica, San Marcos y la Agraria; ahí está sobre todo ese magnífico Archivo Agrario creado por la iniciativa de peruanos (Bonilla, Rodríguez Pastor) e intelectuales extranjeros (Hobsbawn, Martínez Allier). Sus esfuerzos no han sido registrados porque de hecho exigen no un volumen, sino varios. Todavía más: Es tanto lo avanzado que reclama la urgente e inmediata formación de un verdadero centro de información agraria.

Pero esas ausencias nada quitan a esta primera compilación, Kapsoli ha sabido, en primer término, escoger una época con duración suficientemente larga - casi cien años - como para hacerla significativa. Mientras que geográficamente las referencias cubren casi todo el territorio nacional desde Ancash, Huánuco, Lambayeque hasta Puno, Arequipa y Cusco. Espacios y tiempos de conveniente amplitud; y, gran apertura temática que incluye desde las comunidades andinas hasta las haciendas modernas, los latifundios tradicionales y las colonizaciones capitalistas.

Ojalá que este libro sea leído por estudiantes y profesionales para que tengan una buena herramienta que les permita continuar las investigaciones sobre el sector agrario andino. Muchos creyeron que este sector vendría a menos políticamente con la Reforma Agraria de 1969. Algunos hasta apoyaron esa reforma para disminuir las tensiones en el campo. Otros, aunque fueron sus opositores, pronosticaron un desplazamiento del conflicto social desde el campo hacia la ciudad. Parece, por el contrario que nos acercamos a una crisis generalizada de la sociedad sub-capitalista peruana.

4 Esos seis ensayos son: "Sublevación de Atusparia” de Manuel Valladares y Jean Piel; "Esbozo biográfico de Ezequiel Urviola y Rivero", por Antonio Rengifo; "La oligarquía arequipeña y los movimientos campesinos (1895-1930)", de Alberto Flores Galindo; "Movimientos campesino en Jequetepeque en el siglo XX: Estructura y coyuntura agrarias”, por Manuel Burga; "Breve descripción de las acciones de los campesinos de la hacienda Lauramarca”, por Wilson Reátegui, y "La colonización y la lucha por la tierra en el valle del Pereé”, por Manuel Manrique. 

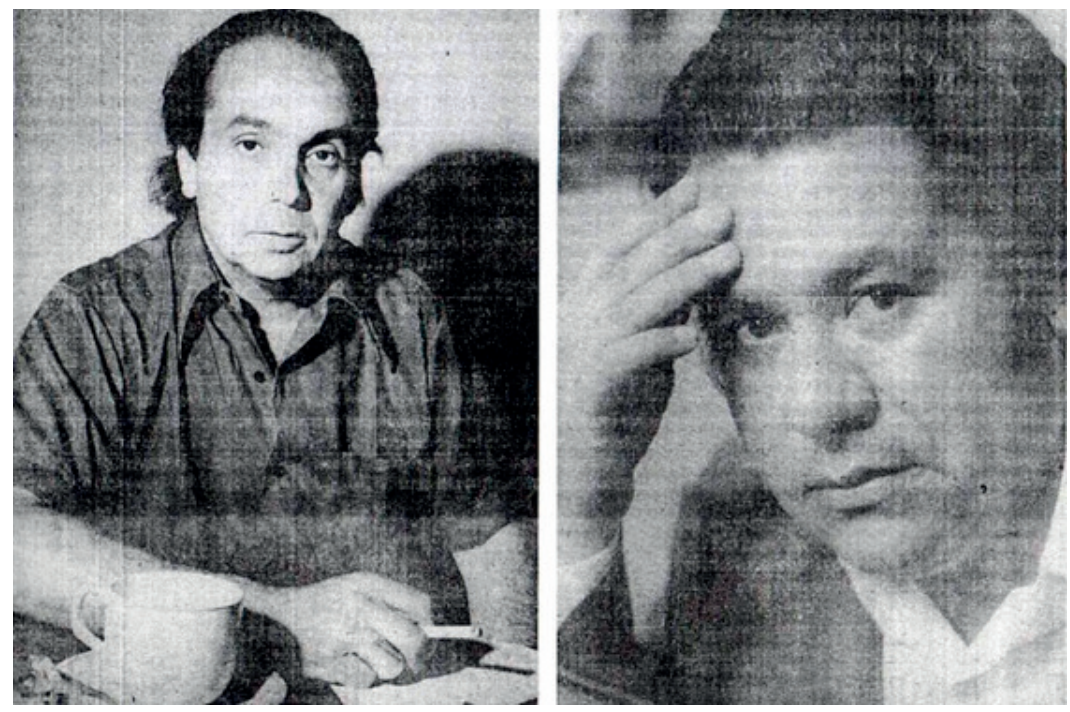

Pablo Macera: «quienes estudian nuestro campesinado no están haciendo una obra puramente intelectual. Su trabajo es comparable al de los auténticos y escasos planificadores sociales» (A la derecha, W. Kapsoli)

Dentro de 25 años, es decir a la vuelta de la esquina, Lima tendrá 15’000.000 de habitantes, o sea tanto como todo el Perú actual. Y salvo la desesperación de algunos arquitectos y sociólogos nada o muy poco se está haciendo para esa gran emergencia demográfica. Se piensa en elecciones o contra elecciones, en el movimiento pendular democracia - dictadura y nada más. Los peruanos como sabemos, somos tan buenos creyentes que confiamos en que Dios es Peruano y resolverá nuestros problemas, ya que nuestros políticos no parecen capacitados para hacerlo. Pero al lado de esta megaurbe donde tomar un vaso de agua resultará más difícil de lo que hoy día es bañarse, también llegarán a su máxima tensión los problemas del campo. Porque al desaparecer la hacienda no han terminado allí los conflictos; y porque se está produciendo un nuevo proceso de diferenciación interna de clases en el campo peruano.

Quienes estudian por consiguiente nuestro campesinado no están haciendo una obra puramente intelectual. Al igual que los auténticos y escasos planificadores sociales que quieren pensar nuevos espacios y soluciones para nuestra ciudad del futuro, estos investigadores del campo también contribuyen positivamente a la creación de una nueva sociedad. Esperemos que los huaicos políticos no le caigan encima mitad de su camino.

\section{Pablo Macera}

Publicado online: $27 / 12 / 2021$ 